\title{
Relations between Remembered Childhood Parental Acceptance-Rejection, Current Fear of Intimacy, and Psychological Adjustment among Pakistani Adults
}

\author{
Abdul Khaleque ${ }^{1 *}$, Sadiq Hussain², Sana Gul' ${ }^{2}$ and Samar Zahra² \\ ${ }^{1}$ Department of Human Development and Family Studies, University of Connecticut, USA \\ ${ }^{2}$ Department of Behavioral Sciences, Karakoram International University, Pakistan
}

Submission: October 02, 2018; Published: December 11, 2018

*Corresponding author: Abdul Khaleque, PhD, Department of Human Development and Family Studies, Unit 1058, University of Connecticut, 348 Mansfield Road Storrs, CT 06269-2058, USA

\begin{abstract}
This study examined the relations between remembered childhood parental acceptance-rejection, fear of intimacy, and psychological adjustment in adulthood among Pakistani young, middle, and older adults. The sample consisted of a total of 366 (55.7\% females) participants from Gilgit-Baltistan (GB) in Pakistan. Among them 182 were young adults (60.9\% females), 92 middle adults (52.1\% females), and 92 older adults (48.9\% females). The samples responded to 5 self-report measures: Adult Parental Acceptance-Rejection Questionnaire for mothers and fathers (short forms), Interpersonal Relationship Anxiety Questionnaire, Adult Personality Assessment Questionnaire (short form), and Fear of Intimacy Scale. Results showed that only male young adults perceived to be more rejected by their mothers and fathers as compared to female young adults. Rejected adults (by both mother \& father) reported higher levels of psychological maladjustment, interpersonal relationship anxiety, and fear of intimacy than did accepted adults in all age groups, except older adults.

Remembered paternal and maternal acceptance-rejection were significantly correlated with psychological adjustment, interpersonal relationship anxiety, and fear of intimacy for both male and female respondents of all age groups, except older adults. Psychological adjustment and interpersonal relationship anxiety were significantly correlated with fear of intimacy for both male and female respondents of all age groups, except for female older adults. Hierarchical regression analysis revealed that paternal acceptance and psychological adjustment made significant independent contributions for the fear of intimacy of young and middle adults. Maternal acceptance made significant independent contribution for only young adults' psychological adjustment, but paternal acceptance made significant independent contributions for young and older adults' psychological adjustment.
\end{abstract}

Keywords: Parental acceptance rejection; Fear of intimacy; Psychological adjustment; Young adults; Middle adults; Older adults

\section{Introduction}

Intimacy refers to an individual's emotionally close and deep personal relationship with a partner. This is a kind of attachment relationship characterized by mutual love, affection, care, concern, sense of happiness, well-being, and emotional security between intimate partners Khaleque [1]. An intimate partner is a significant other as well as an attachment figure Khaleque [2]. Some people may be afraid of forming intimacy with another individual for different reasons including childhood experiences of rejection by attachment figures, such as parental rejection Rohner [3]. According to interpersonal acceptance and rejection theory (IPAR Theory), fear of intimacy (FOI) refers to an individual's anxiousness or reluctance of forming intimate relationship and disclosing or exchanging personal information, thoughts, and feelings with a significant other who is uniquely important to him/her Rohner [3].
Interpersonal acceptance-rejection theory is an evidencebased theory of socialization and life span development that attempts to predict and explain cross-cultural causes, correlates, and consequences of interpersonal acceptance-rejectionespecially parental acceptance-rejection [4]. Rejected individuals often anxiously construct mental images of personal relationships as being untrustworthy, unsafe, unpredictable, or hurtful, and they are likely to develop a fear of intimacy [5].

The experience of parental rejection in childhood is found to be associated with emotional unresponsiveness, impaired selfesteem, and negative worldview, where rejected persons tend to perceive interpersonal relationships as being psychologically and emotionally unsafe, untrustworthy, and negative in other ways [5]. Because negative personality dispositions are known 
to be linked worldwide to the experience of parental rejection in childhood [6], interpersonal acceptance-rejection theory predicts that adults' (both men's and women's) remembrances of parental (both maternal and paternal) rejection in childhood are likely to be associated with the fear of intimacy in adulthood, as mediated by the adults' current level of psychological maladjustment including relationship anxiety [4].

Several studies showed that remembrances of parental acceptance and rejection in childhood independently predicted psychological adjustment of young adults $[7,8]$ and a study on fear of intimacy in married adults [9] found that adults' remembrances of parental rejection in childhood independently predicted their psychological adjustment, relationship anxiety, and fear of intimacy in 13 countries of the world. Intimacy poses great risk for emotional injuries because it involves personal information that individual does not want to share publically [10]. Hook et al. [11] reported four specific components of intimacy--- love and affection, personal validation, trust, and self-disclosure. Intimacy is a phenomenon that is both wanted and feared. People get involved in different kind of activities and techniques under different settings ranging from online dating services to religious groups with an objective to establish intimate relationship. Those who are seeking intimate relationships often worry and fear about the process and its possible outcomes [12]. Fear of intimacy is a subdued capacity of an individual to exchange thoughts and feelings of deeply personal nature with highly valued another person because of anxiety [13]. In 1984, Hatfield discussed the concept and its different components such as; cognitive component i.e. intimates' willingness to disclose their information with one another, emotional component which encompasses partners' deep care about one another in form of like and love, and physical component wherein intimates feel comfortable in close physical proximity.

A satisfied intimate relation stimulates creativity, productivity, emotional regulation including contentment and wellbeing, happiness and meaning in one's life [14]. The inability to form intimate relationships or fear of intimacy is associated with poor psychological adjustment, low level of wellbeing, low selfesteem, psychological distress, illness, and depression $[11,13,15]$. Researchers have found that fear of intimacy associated with several undesirable outcomes in adulthood. For example, fear of intimacy and intimacy deficits were associated with very serious issues like rape and child molestation [16], fear of intimacy was significantly correlated with marital dissatisfaction and this relationship was fully moderated by attachment styles like secure and insecure, indicating the importance of early childhood experience in the development of fear of intimacy [17].

In a study Phillips et al. [18] found that both maternal and paternal care were significantly associated with participants' reported fear of intimacy. In the same study, linear regression analysis revealed that parental care was a significant predictor of participants' fear of intimacy. Additionally, participants with two caring parents reported lowest levels of fear of intimacy as compared to participants with one caring parent and/or no caring parent. Other researchers also supported the importance of childhood maternal care in adults' current fear of intimacy [19].

From the reviewed literature, it appears that individuals' fear of intimacy in adulthood tends to be associated with their relationship patterns with parents during their childhood as construed in IPAR Theory. Although many studies explored relations between remembered childhood parental acceptancerejection, fear of intimacy, and psychological adjustment in adulthood, very few or none of these studies so far explored such relationships at different stages of adults' life. Therefore, the present study was conducted to examine if there are relations between remembered childhood parental acceptance-rejection, fear of intimacy, and psychological adjustment among Pakistani young, middle, and older adults.

\section{Method}

\section{Participants}

The present study sample consisted of total of 366 (55.7\% females) participants from Gilgit-Baltistan (GB) in Pakistan. Among them 182 were young adults (60.9\% females), 92 middle adults $(52.1 \%$ females), and 92 older adults (48.9\% females). Majority of the young adults (55.4\%), middle adults (52.1\%), and older adults (38.6\%) had on average 14 years' education; and few of the young adults (7.6\%), middle adults (4.3\%), and older adults (21.5\%) were illiterates. Most of the young adults (56.5\%), middle adults (63.0\%), and older adults (63.6\%) reportedly belonged to joint family system. The majority of the respondents are from middle class family.

\section{Measures}

Demographic Information Form: An adaptation of the Personal Information Form [20] was used to obtain demographic information of participants.

Adult Parental Acceptance-Rejection Questionnaire (PARQ): Father and Mother-Short Forms [20]. PARQ father and mother were used to assess participants perceived childhood parental acceptance-rejection in this study. Both the questionnaires are identical except that one is related to father and the other is related to mother. Both questionnaires assess four domains of parental acceptance and rejection such as warmth/affection (e.g. my father/mother said nice things about me), hostility/aggression (e.g. my father/mother said many unkind things to me), indifference/neglect (e.g. my father/mother paid no attention to me), and undifferentiated rejection (e.g. my father/mother seemed to dislike me). The items of the entire scales are rated on fourpoint Likert scale ranging from almost always true (4) to almost never true (1). Aggregate score on all the four subscales indicate parental acceptance and rejection in which a higher means lower acceptance and vice-versa. Mean coefficient alphas of the PARQ based on samples from 13 countries were .93 and .90 for mother and father versions, respectively [21]. In this study, the Cronbach's alphas were .82 for mother and .80 for father. 
Interpersonal Relationship Anxiety Questionnaire (IRAQ): IRAQ [22] was used in this study to assess participants' current level of interpersonal relationship anxiety. This questionnaire has nine words/phrases (e.g. stressed, scared etc.) to be rated on four-point Likert scale ranging from almost always true (4) to almost never true (1). Level of interpersonal relationship anxiety increases with the increase in score. The coefficient alpha for IRAQ ranged from .87 to .88 in several researches in different countries [23-25]. The coefficient alpha in this study was .78.

Adult Personality Assessment Questionnaire (PAQ) Short Version: PAQ [20] was used to assess participants' current level of psychological mal/adjustment. This questionnaire has seven sub-scales including hostility/aggression (e.g. I feel resentment against people), dependency (e.g. I like my parents to give me a lot of attention), negative self-esteem (e.g. I get unhappy with myself), negative self-adequacy (e.g. I feel I cannot do things well), emotional unresponsiveness (e.g. I have difficulty showing people how I feel), emotional instability (e.g. I get upset when things go wrong), and negative worldview (e.g. I see life as full of dangers). The items of the entire scale are rated on four-point Likert scale ranging from almost always true (4) to almost never true (1). A higher total score in all seven sub-scales indicate lower psychological maladjustment and vice-versa. Findings of several studies shows that coefficient alpha for PAQ ranges from .81 to .91 $[20,21]$. In this study the Cronbach's alpha was .80 .

Fear of Intimacy Scale (FIS): The fear of intimacy scale [13] has 35 items to be rated on five-point Likert scale ranging from not at all true of me (1) to extremely true of me (5). This scale is administered to measure participants' fear of intimacy (e.g. I would feel comfortable keeping very personal information to myself,). Higher score indicates higher level of fear of intimacy and lower score indicates lower level of fear of intimacy. According to Descutner et al. [13] FIS has a good level of reliability and validity. In this study the coefficient alpha was .86.

\section{Procedure}

To collect the data for this study, the targeted participants were approached in different settings such as their homes, work places, educational institutions etc. After getting their consent the Urdu versions of above-mentioned scales were individually administered to the participants.

\section{Results}

As shown in Table 1, gender differences were significant for perceived maternal and paternal acceptance only for young adults. It revealed that young male adults perceived to be more rejected by their mother and father than female adults.

Table 1: Gender Differences in Measures of Perceived Maternal and Paternal Acceptance, Psychological Adjustment, Interpersonal Relationship Anxiety, and Fear of Intimacy for Young, Middle, and Older Adults.

\begin{tabular}{|c|c|c|c|c|c|c|c|c|c|c|}
\hline \multirow{2}{*}{ Measures } & \multirow{2}{*}{ Gender } & \multicolumn{3}{|c|}{ Young Adults } & \multicolumn{3}{|c|}{ Middle Adults } & \multicolumn{3}{|c|}{ Older Adults } \\
\hline & & M & SD & $\mathrm{t}$ & M & SD & $\mathrm{t}$ & M & SD & $\mathbf{t}$ \\
\hline \multirow{2}{*}{ PARQ-M } & Males & 52.46 & 14.1 & $3.0^{* *}$ & 48.95 & 15.7 & 0.13 & 50.66 & 15.1 & 0.36 \\
\hline & Females & 45.71 & 14.9 & & 48.52 & 15.9 & & 49.53 & 14.5 & \\
\hline \multirow{2}{*}{ PARQ.F } & Males & 50.38 & 14.8 & $1.9^{*}$ & 48.32 & 13.9 & 0.15 & 51.34 & 13.1 & 0.75 \\
\hline & Females & 46.33 & 12.2 & & 47.85 & 14.5 & & 49.36 & 11.9 & \\
\hline \multirow{2}{*}{ PAQ } & Males & 100 & 11.8 & 1.1 & 99.27 & 13.9 & 0.31 & 100.6 & 12.4 & 1.8 \\
\hline & Females & 97.89 & 12.3 & & 100 & 9.2 & & 95.47 & 14 & \\
\hline \multirow{2}{*}{ IRAQ } & Males & 21.13 & 4 & 0.09 & 20.64 & 5 & 1.1 & 22.17 & 3.7 & 1.6 \\
\hline & Females & 21.19 & 4.5 & & 21.83 & 4.6 & & 20.78 & 4.1 & \\
\hline \multirow{2}{*}{ FIS } & Males & 90.06 & 20 & 0.53 & 88.41 & 18.3 & 0.02 & 90.66 & 18.5 & 1.3 \\
\hline & Females & 88.59 & 16.5 & & 88.5 & 18.8 & & 95.93 & 19 & \\
\hline
\end{tabular}

Note: Young adult (male=71, female=111), middle adult (male=44, female=48), older adult (male=47, female=45). ${ }^{*} \mathrm{p}<.05 .{ }^{* *} \mathrm{p}<.01$.

Table 2: Comparison on Psychological Adjustment, Interpersonal Relationship Anxiety, and Fear of Intimacy between Accepted and Rejected Young, Middle, and Older Adults by their Mother.

\begin{tabular}{|c|c|c|c|c|c|c|c|c|c|c|}
\hline \multirow{2}{*}{ Measures } & \multirow{2}{*}{ Group } & \multicolumn{3}{|c|}{ Young Adults } & \multicolumn{3}{|c|}{ Middle Adults } & \multicolumn{3}{|c|}{ Older Adults } \\
\hline & & $\mathbf{M}$ & SD & $\mathbf{t}$ & M & SD & $\mathbf{t}$ & $\mathbf{M}$ & SD & $\mathbf{t}$ \\
\hline \multirow{2}{*}{ PAQ } & Accepted & 92.72 & 12.8 & $7.0^{* *}$ & 94.61 & 11.4 & $4.6^{* *}$ & 91.78 & 13.6 & $4.4^{* *}$ \\
\hline & Rejected & 104 & 8.6 & & 104.7 & 9.5 & & 103.2 & 10.9 & \\
\hline \multirow{2}{*}{ IRAQ } & Accepted & 18.87 & 4.4 & $7.5^{* *}$ & 19.5 & 5.5 & $3.7^{* *}$ & 19.85 & 4.1 & $3.7^{* *}$ \\
\hline & Rejected & 23.18 & 3.1 & & 23 & 3.2 & & 22.8 & 3.3 & \\
\hline \multirow{2}{*}{ FIS } & Accepted & 79.25 & 15.7 & $8.1^{* *}$ & 77.85 & 16.4 & $6.7^{* *}$ & 88.1 & 21.8 & $2.4^{*}$ \\
\hline & Rejected & 97.85 & 15 & & 99 & 13.7 & & 97.37 & 14.9 & \\
\hline
\end{tabular}

Note: Young adult (accepted=85, rejected=97), middle adult (accepted=46, rejected=46), older adult (accepted=41, rejected=51). ${ }^{*} p<.05 .{ }^{* *} p<.01$. 


\section{Psychology and Behavioral Science International Journal}

Table 3: Comparison on Psychological Adjustment, Interpersonal Relationship Anxiety, and Fear of Intimacy between Accepted and Rejected Young, Middle, and Older Adults by their Father.

\begin{tabular}{|c|c|c|c|c|c|c|c|c|c|c|}
\hline \multirow{2}{*}{ Measures } & \multirow{2}{*}{ Group } & \multicolumn{3}{|c|}{ Young Adults } & \multicolumn{3}{|c|}{ Middle Adults } & \multicolumn{3}{|c|}{ Older Adults } \\
\hline & & $\mathbf{M}$ & SD & $\mathbf{t}$ & $\mathbf{M}$ & SD & t & $\mathbf{M}$ & SD & $\mathbf{t}$ \\
\hline \multirow{2}{*}{ PAQ } & Accepted & 94.2 & 12.1 & $4.8^{* *}$ & 94.66 & 10.5 & $4.3^{* *}$ & 91.08 & 12 & $4.5^{* *}$ \\
\hline & Rejected & 102.5 & 10.9 & & 104.2 & 10.7 & & 102.8 & 12.2 & \\
\hline \multirow{2}{*}{ IRAQ } & Accepted & 19.32 & 4.6 & $5.7^{* *}$ & 19.5 & 5.6 & $3.5^{* *}$ & 19.65 & 4.1 & $3.8^{* *}$ \\
\hline & Rejected & 22.7 & 3.4 & & 22.88 & 3.3 & & 22.73 & 3.4 & \\
\hline \multirow{2}{*}{ FIS } & Accepted & 78.88 & 15.6 & $8.2^{* *}$ & 77.84 & 16.5 & $6.2^{* *}$ & 90.32 & 23 & 1.2 \\
\hline & Rejected & 97.81 & 15 & & 98.19 & 14.4 & & 95.2 & 15.2 & \\
\hline
\end{tabular}

Note: Young adult (accepted=82, rejected=99), middle adult (accepted=44, rejected=48), older adult (accepted=37, rejected=55).

${ }^{*} p<.05 .{ }^{* *} p<.01$.

In the second step, participants from all three age groups were divided into two groups; first group labeled as accepted group. This group was constituted by participants whose score were less than midpoint on both PARQ mother and father versions and second group labeled as rejected group consisted of participants whose scores were on or above the midpoint on both PARQ mother and father versions Tables $2 \& 3$. Rejected participants (by both mother \& father) from all three age groups reported higher levels of psychological maladjustment, interpersonal relationship anxiety, and fear of intimacy than accepted group, except older adults, where there were not significant differences in fear of intimacy between accepted and rejected participants by their father see (Tables $2 \& 3$ ).

Table 4: Correlations among Maternal and Paternal Acceptance, Psychological Adjustment, Interpersonal Relationship Anxiety, and Fear of Intimacy for Young Adults.

\begin{tabular}{|c|c|c|c|c|c|}
\hline & $\mathbf{1}$ & $\mathbf{2}$ & $\mathbf{3}$ & $\mathbf{4}$ & $\mathbf{5}$ \\
\hline $\begin{array}{c}\text { 1.Perceived Maternal } \\
\text { Acceptance }\end{array}$ & - & $.61^{* *}$ & $.41^{* *}$ & $.56^{* *}$ & $.43^{* *}$ \\
\hline $\begin{array}{c}\text { 2. Perceived Paternal Ac- } \\
\text { ceptance }\end{array}$ & $.76^{* *}$ & - & $.60^{* *}$ & $.58^{* *}$ & $.72^{* *}$ \\
\hline 3. Psychological Adjustment & $.46^{* *}$ & $.42^{* *}$ & - & $.55^{* *}$ & $.56^{* *}$ \\
\hline $\begin{array}{c}\text { 4. Interpersonal Relation- } \\
\text { ship Anxiety }\end{array}$ & $.55^{* *}$ & $.48^{* *}$ & $.56^{* *}$ & - & $.39^{* *}$ \\
\hline 5. Fear of Intimacy & $.54^{* *}$ & $.58^{* *}$ & $.42^{* *}$ & $.36^{* *}$ & - \\
\hline
\end{tabular}

Note: Coefficients above the diagonal are for males $(n=71)$, and below the diagonal are for females (111).

${ }^{*} p<.05 .{ }^{* *} p<.01$.

Table 5: Intercorrelations among Maternal and Paternal Acceptance, Psychological Adjustment, Interpersonal Relationship Anxiety, and Fear of Intimacy for Middle Adults.

\begin{tabular}{|c|c|c|c|c|c|}
\hline & $\mathbf{1}$ & $\mathbf{2}$ & $\mathbf{3}$ & $\mathbf{4}$ & $\mathbf{5}$ \\
\hline $\begin{array}{c}\text { 1.Perceived Maternal Accep- } \\
\text { tance }\end{array}$ & - & $.43^{* *}$ & $.30^{*}$ & $.38^{* *}$ & $.39^{* *}$ \\
\hline $\begin{array}{c}\text { 2. Perceived Paternal Accep- } \\
\text { tance }\end{array}$ & $.74^{* *}$ & - & $.54^{* *}$ & $.50^{* *}$ & $.47^{* *}$ \\
\hline 3. Psychological Adjustment & $.60^{* *}$ & $.40^{* *}$ & - & $.42^{* *}$ & $.42^{* *}$ \\
\hline $\begin{array}{c}\text { 4. Interpersonal Relationship } \\
\text { Anxiety }\end{array}$ & $.59^{* *}$ & $.50^{* *}$ & $.44^{* *}$ & - & $.30^{*}$ \\
\hline 5. Fear of Intimacy & $.58^{* *}$ & $.76^{* *}$ & $.53^{* *}$ & $.42^{* *}$ & - \\
\hline
\end{tabular}

Note: Coefficients above the diagonal are for males $(n=44)$ and below the diagonal are for females (48).

${ }^{*} \mathrm{p}<.05 .{ }^{* *} \mathrm{p}<.01$.
Maternal and paternalacceptance were significantly correlated with psychological adjustment, interpersonal relationship anxiety, and fear of intimacy for both males and females of all age groups except for older adults, where there were no significant correlations between paternal acceptance and fear of intimacy for both males and females and maternal acceptance and fear of intimacy only for females. (Tables 4-6). Psychological adjustment and interpersonal relationship anxiety were significantly correlated with fear of intimacy for respondents of both genders of all age groups except for female older adults, where there was not significant relationship between psychological adjustment and interpersonal relationship anxiety and fear of intimacy.

Table 6: Intercorrelations among Maternal and Paternal Acceptance, Psychological Adjustment, Interpersonal Relationship Anxiety, and Fear of Intimacy for Older Adults.

\begin{tabular}{|c|c|c|c|c|c|}
\hline & $\mathbf{1}$ & $\mathbf{2}$ & $\mathbf{3}$ & $\mathbf{4}$ & $\mathbf{5}$ \\
\hline $\begin{array}{c}\text { 1.Perceived Maternal Accep- } \\
\text { tance }\end{array}$ & - & $.69^{* *}$ & $.51^{* *}$ & $.56^{* *}$ & $.29^{*}$ \\
\hline $\begin{array}{c}\text { 2. Perceived Paternal Accep- } \\
\text { tance }\end{array}$ & $.45^{* *}$ & - & $.64^{* *}$ & $.63^{* *}$ & 0.15 \\
\hline 3. Psychological Adjustment & $.33^{*}$ & $.72^{* *}$ & - & $.68^{* *}$ & $.30^{*}$ \\
\hline $\begin{array}{c}\text { 4. Interpersonal Relation- } \\
\text { ship Anxiety }\end{array}$ & 0.28 & $.44^{* *}$ & $.55^{* *}$ & - & $.29^{*}$ \\
\hline 5. Fear of Intimacy & 0.19 & 0.17 & 0.11 & 0.03 & - \\
\hline
\end{tabular}

Note: Coefficients above the diagonal are for males $(n=47)$ and below the diagonal are for females (45).

${ }^{*} \mathrm{p}<.05 .{ }^{* *} \mathrm{p}<.01 .1$

Hierarchical regression analysis revealed that only paternal acceptance and psychological adjustment made significant independent contribution for the fear of intimacy of young and middle adults (Table 7).

Forty-five and forty-four percent of the variance in fear of intimacy were accounted for by these variables for young and middle adults respectively (Table 7). When psychological adjustment was entered as dependent variable, maternal acceptance made significant and independent contribution for the psychological adjustment of only young adults, paternal acceptance made significant and independent contribution for the psychological adjustment of young and older adults, and fear of intimacy made significant and independent contribution for the psychological adjustment of young and middle adults. (Table 8). 


\section{Psychology and Behavioral Science International Journal}

Table 7: Hierarchical Regression Analysis Predicting Young, Middle, and Older Adults Fear of Intimacy.

\begin{tabular}{|c|c|c|c|c|c|c|c|c|c|}
\hline \multirow{2}{*}{ Predictors } & \multicolumn{3}{|c|}{ Young Adults } & \multicolumn{3}{c|}{ Middle Adults } & \multicolumn{3}{c|}{ Older Adults } \\
\cline { 2 - 10 } & $\beta$ & $\mathbf{R 2}$ & $\Delta \mathbf{P}^{\prime \prime}$ & $\beta$ & $\mathbf{R}^{2}$ & $\Delta \mathbf{P}^{\prime \prime}$ & $\beta$ & $\mathbf{R}^{2}$ & $\Delta \mathbf{P}^{\prime \prime}$ \\
\hline Step 1 & & 0 & 0 & & 0 & -0.01 & & 0.02 & 0 \\
\hline Gender & -0.04 & & & 0.02 & & & 0.14 & \\
\hline Step 2 & & 0.45 & 0.44 & & 0.44 & 0.41 & & 0.09 & \\
\hline PARQ-M & 0.03 & & & 0.14 & & & 0.22 & \\
\hline PARQ.F & $.52^{* *}$ & & & $.45^{* *}$ & & & -0.07 & & \\
\hline PAQ & $.20^{* *}$ & & & $.18^{*}$ & & & 0.15 & \\
\hline
\end{tabular}

Note: ${ }^{*} p<.05 .{ }^{* *} p<.01$.

Table 8: Hierarchical Regression Analysis Predicting Young, Middle, and Older Adults Psychological Adjustment.

\begin{tabular}{|c|c|c|c|c|c|c|c|c|c|}
\hline \multirow{2}{*}{ Predictors } & \multicolumn{3}{|c|}{ Young Adults } & \multicolumn{3}{c|}{ Middle Adults } & \multicolumn{3}{c|}{ Older Adults } \\
\cline { 2 - 10 } & $\beta$ & $\mathbf{R}^{\mathbf{2}}$ & $\Delta \mathbf{P}^{\prime \prime}$ & $\beta$ & $\mathbf{R}^{2}$ & $\Delta \mathbf{P}^{\prime \prime}$ & $\beta$ & $\mathbf{R}^{\mathbf{2}}$ & $\Delta \mathbf{P}^{\prime \prime}$ \\
\hline Step 1 & & 0 & 0 & & 0 & -0.01 & & 0.03 & 0.02 \\
\hline Gender & -0.08 & & & 0.03 & & & -0.19 & \\
\hline Step 2 & & 0.31 & 0.29 & & 0.28 & 0.25 & & 0.48 & 0.46 \\
\hline PARQ-M & $.17^{*}$ & & & 0.16 & & & 0.01 & \\
\hline PARQ.F & $.20^{*}$ & & & 0.22 & & & $.64^{* *}$ & & \\
\hline FIS & $.26^{* *}$ & & & $.23^{*}$ & & & 0.09 & & \\
\hline
\end{tabular}

Note: ${ }^{*} p<.05 .{ }^{* *} p<.01$.

Along with other predictors maternal acceptance explained $31 \%$ variance for young adults' psychological adjustment, paternal acceptance along with other predictors explained $48 \%$ variance in psychological adjustment of older adults, and fear of intimacy along with other predictors explained $28 \%$ variance in psychological adjustment of middle adults (Table 8).

\section{Discussion}

The present study intended to test IPAR Theory's prediction that remembrances of parental rejection in childhood influence fear of intimacy and psychological adjustment in adulthood. Results showed that rejected adults (by both mother \& father) reported higher level of fear of intimacy than did accepted adults in all age groups, except older adults. Hierarchical regression analysis revealed that only paternal acceptance and psychological adjustment made significant independent contributions for the fear of intimacy of young and middle adults. Two studies on Pakistani samples partially support our findings. For example, one study showed that married men's remembrances of paternal and maternal acceptance in childhood predicted their fear of intimacy but for women only maternal acceptance predicted their fear of intimacy [9]. Another study showed that remembrances of paternal acceptance in childhood and psychological adjustment predicted married women's fear of intimacy while remembrance of maternal acceptance in childhood and psychological adjustment predicted married men's fear of intimacy and maternal acceptance in childhood predicted unmarried men's fear of intimacy [26].

International literature in this field also supports findings of the present study. For example, in Greece, remembrances of parental (both maternal \& paternal) acceptance in childhood predicted both men and women's fear of intimacy $[27,28]$. In Turkey, remembrance of maternal acceptance in childhood was significantly correlated with both men and women's fear of intimacy but paternal acceptance was significantly correlated only with men's fear of intimacy. Psychological adjustment of both men and women participants made a significant contribution to their fear of intimacy [29]. Remembrances of both maternal and paternal acceptance in childhood and current psychological adjustment contributed significantly to African American college students' fear of intimacy [30]. Childhood remembrances of paternal and maternal acceptance and current psychological adjustment made significant contribution to the fear of intimacy of Latino American university students [31]. Australian and Polish adults' remembrances of parental acceptance in childhood and current psychological adjustment were significantly correlated with their fear of intimacy [32]. In Portugal, only men's fear of intimacy was predicted by their remembrances of childhood maternal acceptance and women were less likely to suffer the negative consequences of parental rejection during childhood on their adulthood fear of intimacy [33]. Contradictory evidences reported by Glavak Tkalic et al. [34] from Croatia where parental acceptance in childhood failed to predict either men or women's fear of intimacy.

Additionally, the present findings showed that rejected adults (by both mother \& father) reported higher levels of psychological maladjustment and interpersonal relationship anxiety than did accepted adults in all age groups, except older adults but maternal acceptance made significant and independent contribution for only young adults' psychological adjustment and paternal acceptance made significant independent contributions for young and older adults' psychological adjustment. We don't have any clear explanation why remembered childhood parental rejection are not significantly related with psychological maladjustment and interpersonal relationship anxiety of older adults. This may 


\section{Psychology and Behavioral Science International Journal}

be due to the fading memory of the older adults about childhood experiences.

Further research is needed to find a clear answer to this question. However, past researchers reported consistent findings that remembrances of paternal and maternal acceptance in childhood predicted young adults' psychological adjustment [35], perceived paternal acceptance in childhood was a significant predictor of university students' psychological adjustment [7], maternal and paternal acceptance were significant predictors of school students' reported alexithymia [8], accepted children by their fathers and mothers reported higher level of psychological adjustment and lower level of misconduct as compared to those children who perceived to be rejected by their parents [36]. Studies on clinical population showed that paternal rejection in childhood has significant effects on depression, mania, and psychosis during adulthood [37]. In addition, maladjusted convicts were found to report experiences of parental rejection during childhood [38].

Cross-cultural research literature on this topic also supports findings of the present study. For example, remembrances of parental acceptance in childhood predicted current psychological adjustment in Turkey [39], Estonia [40], Bangladesh [41], India [42], and Kuwait [43]. Meta-analyses of cross-cultural and intracultural studies showed that parental acceptance during childhood has significant developmental outcomes during adolescence and adulthood including psychological maladjustment, and social, emotional, cognitive, and behavioral development, regardless of race, ethnicity, culture, gender, and geographical region of the world [44].

Furthermore, the present findings that male young adults perceived to be more rejected by their mother and father as compared to female young adults is consistently supported by several other studies. For example, more men than women, irrespective of their clinical status (clinical \& non-clinical sample), reported to be rejected by their fathers than mothers during childhood $[15,45]$ and more boys than girls reported to be rejected by their fathers $[40,43]$.

To conclude, the findings of the present study seem to partially support the predictions of the IPAR Theory that childhood parental acceptance-rejection and psychological adjustment have significant contributions for the fear of intimacy of adults [4649]. The findings of this study may be useful to the professionals and practitioners, who are concerned with the developmental outcomes of childhood parental acceptance and rejection on later development. We think that clinicians and counsellors who are concerned with the fear of intimacy and psychological maladjustment of adults should take into consideration, among others, their clients' childhood experiences of parental rejection. Having said this, we are also aware of some limitations of the present study such as data for the present study was based only on self-report from a small sample of a tribal subgroup with distinctly different sociocultural identity from the mainstream Pakistani society.

\section{References}

1. Khaleque A (2018) Intimate relationships across the lifespan. Formation, development, enrichment, and maintenance Santa ABCCLIO/Praeger.

2. Khaleque A (2001) Parental acceptance-rejection, psychological adjustment, and intimate adult relationships. Unpublished Master's thesis, University of Connecticut, Storrs, USA.

3. Rohner RP (2005) Parental Acceptance-Rejection Questionnaire (PARQ): Test manual. In: RP Rohner, A Khaleque (Eds.), Handbook for the study of parental acceptance and rejection ( $4^{\text {th }}$ edn.), Storrs CT: Rohner Research Publications P: 43-106.

4. Rohner RP (1986) The warmth dimension: Foundations of parental acceptance-rejection theory. Beverly Hills (Edt.), CA: Sage Publications, India.

5. Rohner RP, Buehler C (2017) Interpersonal acceptance-rejection theory. [Special collection]. Journal of Family Theory \& Review 9(4): 423-520.

6. Khaleque A, Rohner RP (2012) Transnational relations between perceived parental acceptance and personality dispositions of children and adults: A meta-analytic review. Pers Soc Psychol Rev 16(2): 103115 .

7. Hussain S, Munaf S (2011) Father behavior in childhood: the predictor of psychological adjustment in adulthood. FUW Journal of Social Sciences 5(2): 71-85.

8. Hussain S, Ahmad Z (2014) Parental acceptance-rejection as predictor of alexithymia among students in Gilgit-Pakistan. International Journal of Information and Education Technology 4(3): 285-288.

9. Hussain S, Zahra S, Gul S (2016) Remembered childhood parental acceptance-rejection and current fear of intimacy among married adults in Gilgit-Pakistan. Abstracts, $6^{\text {th }}$ International Congress on Interpersonal Acceptance and Rejection, Psychology Faculty UNED, Madrid, Spain.

10. Patrick S, Beckenbach J (2009) Male perceptions intimacy: A qualitative study. The Journal of Men's Studies 17(1): 47-56.

11. Hook MK, Gerstein LH, Detterich L, Gridley B (2003) How close are we? Measuring intimacy and examining gender differences. The Journal of Counseling \& Development 81(4): 462-472.

12. Vangelisti AL, Beck G (2007) Intimacy and fear of intimacy. In LL' Abate (Edt.), Low-cost approaches to promote physical and mental health, New York, NY: Springer, Pp: 395-414.

13. Descutner CJ, Thelen MH (1991) Development and validation of a fearof-intimacy scale. Journal of Consulting and Clinical Psychology 3(2): 218-225.

14. Bartholome K (1990) Avoidance of intimacy: An attachment perspective. Journal of Social and Personal Relationships 7(2): 147178.

15. Thelen MH, Vander Wal JS, Muir Thomas A, Harmon R (2000) Fear of intimacy among dating couples. Behav Modif 24(2): 223-240.

16. Bumby KM, Hansen DJ (1997) Intimacy deficits, fear of intimacy, and loneliness, among sexual offenders. Criminal Justice and Behavior 24(3): 315-331.

17. Besharat MA, Naghshineh N, Ganji P, Tavalaeyan T (2014) The moderating role of attachment styles on the relationship of alexithymia and fear of intimacy with marital satisfaction. International Journal of Psychological Studies 6(3): 106-117.

18. Phillips TM, Wilmoth JD, Wall SK, Peterson DJ, Buckley R, et al. (2013) Recollected parental care and fear of intimacy in emerging adults. The Family Journal: Counseling and Therapy for Couples and Families 21(3): 335-341. 
19. Lloyd ME (2011) Fear of intimacy in romantic relationships during emerging adulthood: the influence of past parenting and separationindividuation (doctorate thesis). Victoria University, Australia.

20. Rohner RP, Khaleque A (2005) Personality Assessment Questionnaire (PAQ): Test manual. In: RP Rohner, A Khaleque (Eds.), Handbook for the study of parental acceptance and rejection ( $4^{\text {th }}$ edn.), Storrs, CT Rohner Research Publications, pp: 187-225.

21. Rohner RP, Carrasco MA (2014) Relation between perceived parental acceptance and children's psychological adjustment in the context of differential parental power and prestige. Cross-Cultural Research $48(30)$.

22. Rohner Research Publications (2012) Retrieved from http:// rohnerresearchpublications.com/1.html.

23. Brown CM (2014) Assessing the reliability of the Interpersonal Relationship Anxiety Questionnaire (IRAQ). Unpublished manuscript.

24. Li X (2013) Internal consistency reliability of the IRAQ. Unpublished manuscript.

25. Naz F, Kauser R (2015) Translation and validation of Interpersonal Relationship Anxiety Questionnaire (IRAQ). FWU Journal of Social Sciences 9(1): 118-126

26. Butt MM, Malik F, Faran M (2016) Remembered parental acceptancerejection and fear of intimacy in married and unmarried men and women in Pakistan. Abstracts, $6^{\text {th }}$ International Congress on Interpersonal Acceptance and Rejection, Psychology Faculty UNED, Madrid, Spain.

27. Giovazolias T (2016) An explanatory path model on the relationship between remembered parental acceptance-rejection and psychological adjustment: The mediating role of rejection sensitivity and fear of intimacy. Abstracts, $6^{\text {th }}$ International Congress on Interpersonal Acceptance and Rejection, Psychology Faculty UNED, Madrid, Spain.

28. Giovazolias TA, Giotsa A (2016) The mediating effect of psychological adjustment and anxiety in the relationship between parental acceptance-rejection and fear of intimacy in Greek young adults. Abstracts, $6^{\text {th }}$ International Congress on Interpersonal Acceptance and Rejection, Psychology Faculty UNED, Madrid, Spain.

29. Kuyumcu B, Ongider-Gregory N, Karadeniz G (2016) Association between remembrances of parental acceptance in childhood and fear of intimacy among young Turkish adults: Mediating effects of anxiety and psychological adjustment. Abstracts, $6^{\text {th }}$ International Congress on Interpersonal Acceptance and Rejection, Psychology Faculty UNED, Madrid, Spain.

30. Lindsey CR, Khan S (2016) Relationship among remembered parental acceptance, psychological adjustment, anxiety, and the fear of intimacy among African American college students. Abstracts, $6^{\text {th }}$ International Congress on Interpersonal Acceptance and Rejection, Psychology Faculty UNED, Madrid, Spain.

31. Melendez-Rhodes T, Plunkett S, Bakhtiari F (2016) Parental acceptancerejection in relation to fear of intimacy in Latino American university students. Abstracts, $6^{\text {th }}$ International Congress on Interpersonal Acceptance and Rejection, Psychology Faculty UNED, Madrid, Spain.

32. Filus A, Rohner RP, Melendez-Rhodes T, Kuyumcu B, Machado F, et al. (2018) Psychological maladjustment mediates the relation between remembrances of parental rejection in childhood and adults' fear of intimacy: A multicultural study. Abstracts, $7^{\text {th }}$ International Congress on Interpersonal Acceptance and Rejection, Panteion University of Social and Political Sciences, Athens Greece.

33. Machado M, Machado F, Neves AS, Favero M (2016) The role of interpersonal acceptance in Portuguese students' fear of intimacy. Abstracts, $6^{\text {th }}$ International Congress on Interpersonal Acceptance and Rejection, Psychology Faculty UNED, Madrid, Spain.
34. Glavak Tkalic R, Vulic Prtoric A, Zoroja A (2016) Parental acceptancerejection in childhood and fear of intimacy in adulthood among Croatian young adults: Moderating effects of anxiety and psychological adjustment. Abstracts, $6^{\text {th }}$ International Congress on Interpersonal Acceptance and Rejection, Psychology Faculty UNED, Madrid, Spain.

35. Najam N, Hussain S, Kanwal RH, Malik F, Kausar R (2014) Parental power, prestige, and acceptance as predictors of young adults' psychological adjustment in Gilgit-Baltistan, Pakistan. Cross-Cultural Research, Pakistan 48(3): 270-277.

36. Munaf S (2015) Parental acceptance and rejection as a determinant of psychological adjustment and conduct of Pakistani adolescents. Journal of Pakistan Psychiatric Society 12(4): 26-28.

37. Hussain S, Alvi T, Zeeshan A, Nadeem S (2013) Perceived childhood paternal acceptance-rejection among adults. Journal of the College of Physicians and Surgeons Pakistan 23(4): 269-271.

38. Sajid B, Riaz MN (2016) Perceived parental rejection and psychological maladjustment: A study of convicts. Journal of Behavioral Sciences 26(2): 39-54.

39. Dural G, Yalcin I (2014) Investigation of relationship between parental acceptance and psychological adjustment among university students. The Journal of Psychiatry and Neurological Sciences 27: 221-232.

40. Tulviste T, Rohner RP (2010) Relationships between perceived teachers and parental behavior and adolescent outcomes in Estonia. Cross-Cultural Research 44(3): 222-238.

41. Rohner RP, Khaleque A, Elias MS, Sultana S (2010) The relationship between perceived teachers and parental acceptance, school conduct, and psychological adjustment of Bangladeshi adolescents. CrossCultural Research 44(3): 239-252.

42. Parmar P, Rohner RP (2010) Perceived teacher and parental acceptance and behavioral control, school conduct, and psychological adjustment among school-going adolescents in India. Cross-Cultural Research 44(3): 253-268.

43. Rohner RP, Parmar P, Ibrahim M (2010) Perceived teachers' acceptance, parental acceptance, behavioral control, school conduct, and psychological adjustment among school-age children in Kuwait. Cross-Cultural Research 44(3): 269-282.

44. Khaleque A, Rohner RP, Riaz MN. Sadeque S (2014) Perceived parental acceptance-rejection and psychological adjustment of children: A cross-cultural study in Finland, Pakistan, and United States. Psychological Studies 52: 114-119.

45. Hussain S, Munaf S (2012) Gender differences in perceived childhood father rejection and psychological adjustment in adulthood. Journal of Behavioral Sciences 22(1): 100-114.

46. Hatfield E (1984) The dangers of intimacy. In: V Derlaga (Edt.), Communication, intimacy, and close relationships New York: Academic Press, New York pp: 207-220.

47. Khaleque A, Rohner RP (2002) Perceived parental acceptance-rejection and psychological adjustment: A meta-analysis of cross-cultural and intracultural studies. Journal of Marriage and Family 64(1): 54-64.

48. Rohner RP, Lansford JE (2017) Deep structure of the human affectional system. Journal of Family Theory and Review 9: 426-440.

49. Roszak J, Filus A, Izadikhan Z (2016) Antecedents of the fear of intimacy among Australian and Polish adults: Remembered parental rejection in childhood. Abstracts, $6^{\text {th }}$ International Congress on Interpersonal Acceptance and Rejection, Psychology Faculty UNED, Madrid, Spain. 


\section{Your next submission with Juniper Publishers will reach you the below assets}

- Quality Editorial service

- Swift Peer Review

- Reprints availability

- E-prints Service

- Manuscript Podcast for convenient understanding

- Global attainment for your research

- Manuscript accessibility in different formats

( Pdf, E-pub, Full Text, Audio)

- Unceasing customer service

Track the below URL for one-step submission

https://juniperpublishers.com/online-submission.php 